\title{
Performing Embodied Pedagogy: Listening to the Small Talk of My Injured Back
}

\author{
Lorna Louise Ramsay \\ Simon Fraser University
}

\begin{abstract}
My poetic inquiry contemplates possible exchanges between educator and learner in a writing intensive university course designed to invite collaborative co-authoring of embodied, emotive, and informed reflective responses to ongoing life narratives and histories expressed/performed. I intend to open up my inclusive learning environment to feelings of belonging, a shared “performance of place," (Kaye, 2000, p. 3) that supports risk-full exploration of embodied texts like those living in and expressing through the small talk of my injured back. I challenge selfmade definitions of educator, learner, and researcher in dedication to critical, informed, contemplative practices around sometimes unexpected, multidisciplined, transmediated places of embodied expression and emergent pedagogy.
\end{abstract}

Keywords: poetic inquiry; embodiment; multiliteracy; reflective practices 


\section{Performing Embodied Pedagogy: Listening to the Small Talk of My Injured Back}

I demonstrate my method of narrative inquiry by describing my embodied responses as I approach a new class of undergraduate students, future teachers. I critically reflect on my selfdefinitions of aesthetic expresser and educator through description of pre-performance postures and I listen to and learn from disquieting, embodied texts living in the small talk of my injured back. I continue my self-reflection as I describe a demonstration of my arts performance for my students, a video of my arts performance at an international conference that I introduce by playing a flute solo. As the video begins, my solo becomes a duet with myself shared in mutual spaces of learning. I invite students to be aware of possible audience/participant collaboration in our writing intensive course, exchanges of informed content, emotive, reflective responses to ongoing narratives of lives lived and histories expressed/performed. My goal is to elicit mutual feelings of belonging to an inclusive community that supports vulnerable expression with nonjudgmental potential visceral reflection, embodied sense of place that may inform selfperceptions of educator and aesthetic expresser. Student narratives emerge from collaboration with drafts born from reflective responses to class texts, literature assignments, peer reviews, and instructor feedback, life-storytelling in multidisciplined interpretations of dynamic themes that require students to explore places of vulnerability and risk. This type of collaboration sustains what Bakhtin (1929/1984) describes as "hidden dialogicality," where "each present, uttered word responds and reacts with its every fibre to the invisible speaker, points to something outside itself, beyond its own limits, to the unspoken words of another person” (p. 197). Through poetic inquiry, I seek and critically consider the unspoken, visceral, pedagogy that negotiates and sustains my students' emergent corporeal narrative histories through transformative interpretations and re-interpretations of multidisciplinary, arts-based expression.

My spine sighs with every step forward

a lower vertebrae speaks to me in familiar places

between fear and exhilaration

I sense an audience suspended

between silence

and

potential sound in my pre-performance preparation

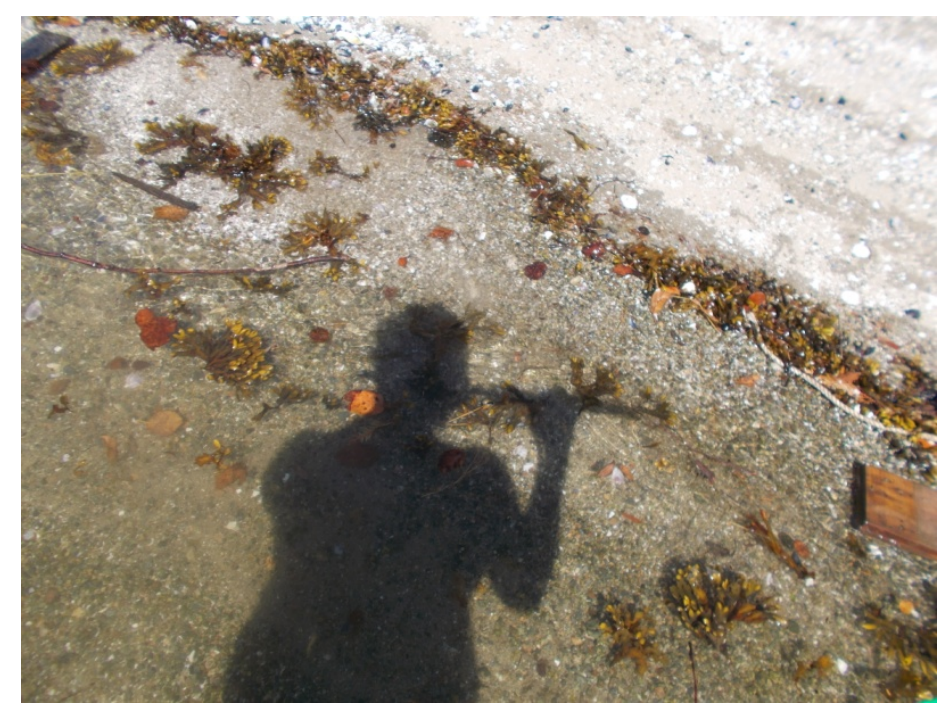


Muscle-tugged to stillness

I breathe deeply in acceptance of my embodied discomfort

my inquiry of disruption

to the obvious, the expected, like a flutist preparing for a well-known solo

and the audience expecting a certain sound

I reach to my audience

to provoke sense of inclusion to sounds

silence

and embodied interpretation of possible pedagogy through my need to share with my new students my art(s) performance to encourage fluidity between performer and audience, to provoke participation, to question intentions, expectations, and interpretations not only of my sound but also of what they might voice in response. As in Cox's (2001) interpretation, "we normally imagine (most often unconsciously) what it is like to make the sounds we are hearing" (p. 205).

I review my purpose through an already questioning body anticipating forward motion towards audience exchange, inclusion as invitation to embodied listening, new ways of voicing

Cox (2001) suggests this interpretation is more than mimetic, rather metaphorical, or suggestive of his or her own experiences with embodied perceptions that as Cox contends do not "belong to a single mode of physical experience” (p. 204).

I count my inhalation, which I send as aesthetically framed comfort to strains of shaped pain: Breath yang in 1, 2, 3-hold to feel, open access to tightness from vertebrae to sacrum, contentious space between pelvis and hip... and slowly exhale to 4, 3, 2, 1

Find natural breathing

I am my perfect self, the yogi says, life is breath and breath is life...

I invite life to my pressing heart and exhale tranquility into my pulsing hip pressing...

Intension is change, I hear the yogi say.

In-tension, I observe my performative mode sink into familiar postures of the past, of sensitivity to other's energies, back straight, flute in hand, orchestra members all around tense with expectation, shallow breathing, waiting for the conductor's entrance. 


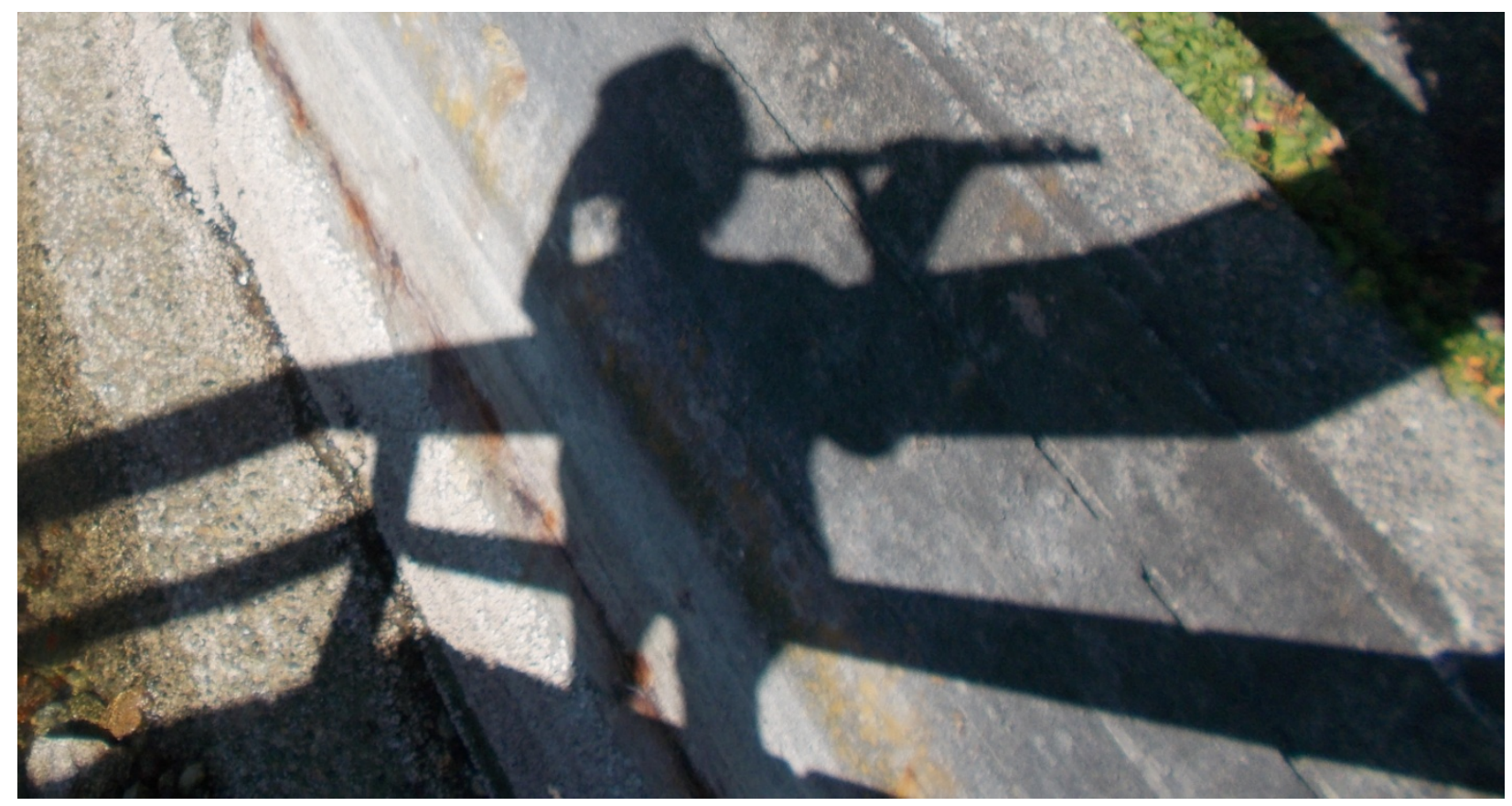

I force focus to here and now, to my imminent introduction as instructor for a university writing intensive course. I do not find tranquility in my concentrated breathing when I pause before approaching the fusion and confusion in chat, chatter of students who arrive at my course between practicum semesters, high school English teachers-to-be. I search inward to my body's invitation to take on history of my professional development since my teacher training, strategies that support a corporeal knowing of developing and emerging postures in contemplative practices.

Be still, the yogi says, and in stillness there is wakefulness. In rest, there is rest-oration

I shift vision to students standing in groups with torsos bent forward, backs arched, legs tightstraight carrying their excited exchanges about their teaching practicum.

I am awake

to the pulse of this group of students

the pulse of my corporeal history of injury, retraining, and re-positioning

Inhaling in and around my ever increasing heartbeat

Slow down

Meaningful inhalation

Seek deep listening with/in

and with/out...

I shift my bag's weight to fascia

heavily knotted below my shoulder

to open paradox of my embodied purpose

where I am headed with places

of interpretation and re-interpretation...and for these students...I hear my yogi self

Yoga is release of effort, expectation, efficiency, excellence. 
My focus in on my left nostril and I feel warm air stroke my left nasal passage, fill my heart dome of energy and I visualize calm behind my heart to the soft protection between vertebrae. I want to re-form my fascia that could rest rigid preventing flexibility and alignment to gentle step into rhythms of my musician's body and this pulsating community of energies.

I move into five fused bones of my sacrum, perfectly formed as no other's perfectly tuned as no other's sound-solid base of my spine With re-vision I transform past sudden moments of impact, harsh intrusion of metal and plastic crashes of place and pace, car, care speed, mistakes softened memory, pliable shifts like gears, like keys and I feel tonality regenerate in meditation and mediation trans-mediation accepting places and spaces where I trust my body's narratives in vividness to feel through performance beyond judgement as my musician self to potential sound my photographer's reinterpretation of shutter speeds sensing sun shifts to perform again in a lens of embodied modulation from key of E minor

$E$ for effort to A major

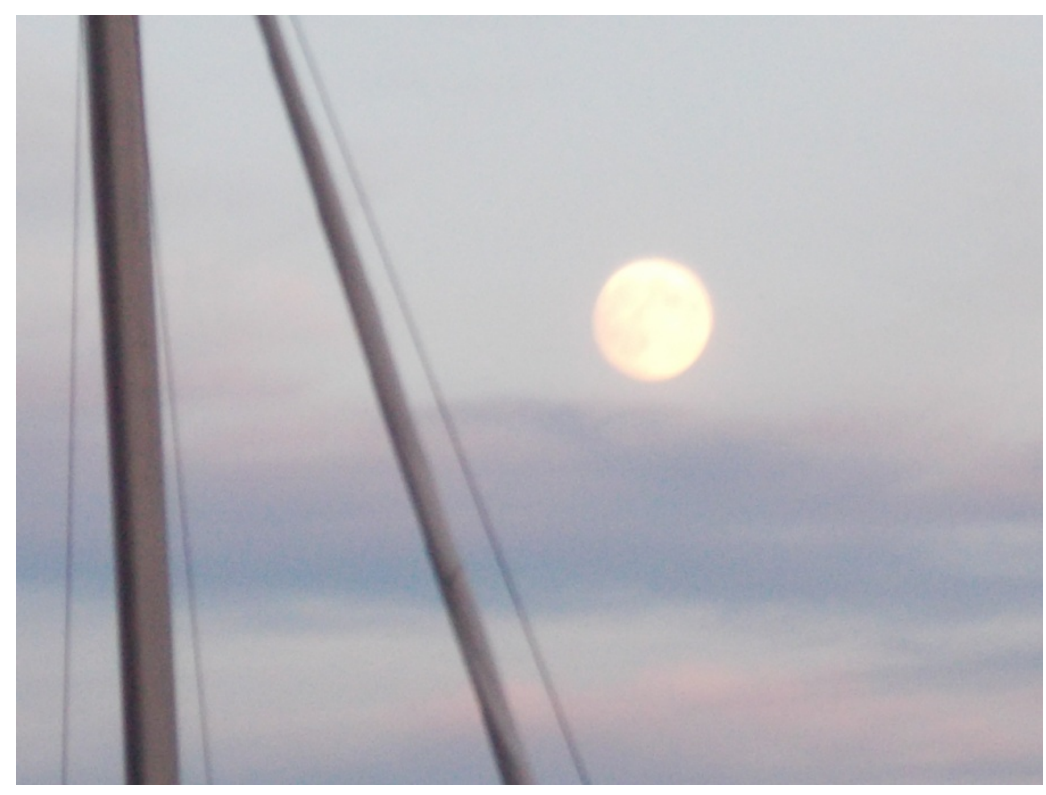

“A” for acceptance, awareness, alive-ness...my body’s alignment

Our aesthetically sensitive environment, the shared places of acoustic sensation invites inquiry for both myself and my students in that "we are still, through perception and self-awareness, part of a single sonic environment” (Corness, 2008, p. 22). With that in mind, I share and encourage avenues of expression through acts of trans-mediation that invite multi-disciplinary textual expression through layers of arts genres. Coles and Barrell (as cited in James, Dobson, \& Leggo, 
2013) describe this approach for students as, "the power to allow them to look directly at one art form and try to capture its essence through the use of another"( p. 111). I demonstrate and elicit visceral responses to the preset-shared environment and potential embodied interpretation of personal history that evokes portals of critically considered pedagogy.

I think of a former student.

Her body moves through acoustic chaos

long brown hair distorting tonality, concealing clear vision

She looks sideways at me, a student defiantly shy

I feel rhythm of humility confused with disappointment

She is a professional photographer and will miss classes for work

Suddenly in potential re-visioning, she becomes a tall, vibrant artist

hair tied back to allow settling of sound, clarity of face-to-face exchange

eyes aware, open and ready to mediate her artistry

I suggest trans-mediation

of photography and narrative to embrace her passion through words

Embrace your art in expanded concepts of literary inquiry

spilling over arts, connect your imagery in ways that make sense to you

like flexible definitions of multi-literacy

in descriptive, emotive language embodied

in strong stance

Reinterpret your narrative processes

Well-observed, deeply felt, performed

My former student, the photographer/English teacher-to-be, carefully prepared well-oiled class photography slide show presentations as she stiffly, quietly, and cautiously formed narratives of distant and lonely description. Her passion like her self-defined identity as photographer/educator required care and attention, a reaching-through to words and feelings, synchronicity, embodied struggle to press in and through aesthetic posturing, intimate photographic art story-ing. Her posture was far from malleable and was slow to re-form, re-join, re-joy-s. I was committed to listen deeply and to provide feedback on drafts that invited my student to fall into her art and feel visceral responses that matter. I remind myself that deep listening de-limits expectation and judgment in aesthetic exchange and with care softens delineating borders within us and between inquiring voices of artist and educator. Snowber, a dancer and educator, suggests, "Listening to the underside of what is happening in a student's life is a sacred act, one that must take form in the soil of mindfulness and loving kindness" (Richmond \& Snowber, 2009, p. 4). My student finally shared a series of photographs of a friend who was seriously ill. Risk-full, she performed through a different type of aliveness. Form and design shifted from the obvious to the subtle, tonality was polyphonic in small details of a smile with shadows teasing light across a hospital bed. Richmond \& Snowber (2009) write,

The gift of art in life is that it arrests me to pay attention to nuances and feelings that I may never have perceived, whether that is the resonances in poetic language or the colours of auburn and burgundy in a painting. Art awakens me, and once again, I am startled into the beauty of being alive. (p. 4) 


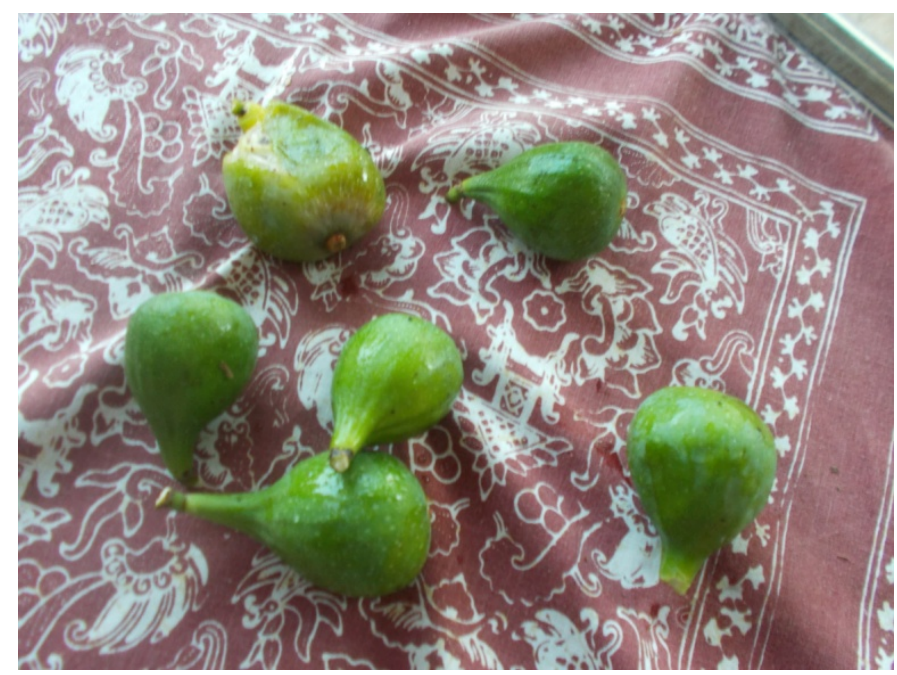

Sound, voice, feeling, and thoughtful interpretation fused through layers of meaning in my student's narratives and with several script revisions, my feedback, and peer reviews, my student began to express through awareness of the textuality of her stories. Photo after photo she felt openings to perform her passion in textual depths, new postures sustained through images of embodied love. As Leggo (as cited in James, Dobson, \& Leggo, 2013) suggests, "We are awash in a sea of textuality... where we try to tame the wildness of language" (p. 181). I facilitate revisioning, re-hearing of possible emotive yet critically informed venues of commitment and vigilance to live and relive, perform, and perform again texts of pedagogy that influence teaching practice. Like Clandinin and Connelly (2000), I suggest this type of narrative inquiry evokes pedagogy and is both content to be analyzed and method to study.

At the doorstep to my new teaching assignment, at the foyer of my next performance, I feel acoustics of my audience through sound and movement and listen more with/in my embodied story before I ask others to access their spaces of contemplation. I refocus my inhalation to deep chest pulse, I visualize light in my heart centre and behind, and follow crackling electric release down my spine to my chakra of creativity, of prana, and exhale heart-tempo with my intention to share, to commit to my belief that pedagogy embodies performance and performance embodies and sustains pedagogy.

Healing is not performance, the yogi says, and I breathe between nodules that protect from chat, chatter of my vertebrae, and I invite sharing of our communal source of breath, invite co- opening

Before I introduce my musician self to my new students, I feel, as in moments before a solo, full depths of my intention

meet pulse of my heart centre to solid spine base

merge exhilaration with total orchestral ambience

and, suddenly fearful, I forget to count before my entrance. I panic and look for a cue.... I feel beyond the university doorframe and find direction from rhythms in excited voices laced with anticipation and expectation. I want to be back in the orchestra and suddenly hear a sweet 
resonance beyond single sound, a solo in synchronicity of tone and pulse penetrating all players' timbre. I want to realize suddenly the soloist in perfect harmony... is me.

I am my perfect self, the yogi says, life is breath and breath is life (I invite life to my pressing heart and exhale rhizome tranquility to irascible small talk of my back)

Intension is change, I hear the yogi say.

I prepare in stillness and wait for a moment, a perfect way through discomfort in this new space to reach towards possibilities that teaching as performance includes audience synchronicity.

I wait.

Students glance at me and smile. I am already smiling, sensing synchronicity, and I raise my eyebrows and feel the invisible string at the base of my neck that gently pulls my crown skywards, my shoulders lower: my spine straightens by itself. I feel a pulse, a beat, information from the acoustic texture and my body senses internal rhythm like the science of synchrony. I think of science writer, Phillip Ball, who suggests that neurons and the subconscious have a hidden order and, by joining millions of neurons, emotion emerges in constant pulse and pattern (CBC, 2013).

Aware of humming vibration of emotion

I exhale into open spaces in muscle tension

Opening hidden order

spaces beyond the physical around me

What is your body telling you today? Find your heart centre, the yogi says

My back reveals

a silent key change to $\mathrm{F}$

$\mathrm{F}$ for fear...

How long can I sustain this pose?

this lower vertebrae

this left leg stretched to its limit of fascia

reforming deep challenge to seek softness

in near pain, perhaps deep pleasure

I listen for a balanced embodied way

into sustainability, sustainable pedagogy

a lasting long breath in...

and slow release

I invite a listening to what can be imagined as music

What comes to mind and body response

when I think of Debussy

I invite listening

I hear the flute solo at the beginning of L'Apres-midi d'un Faune

and wait for meaningful silence from my expectant audience

I forgive and control my impulsive need to use words immediately, any words, to be heard as I hear 


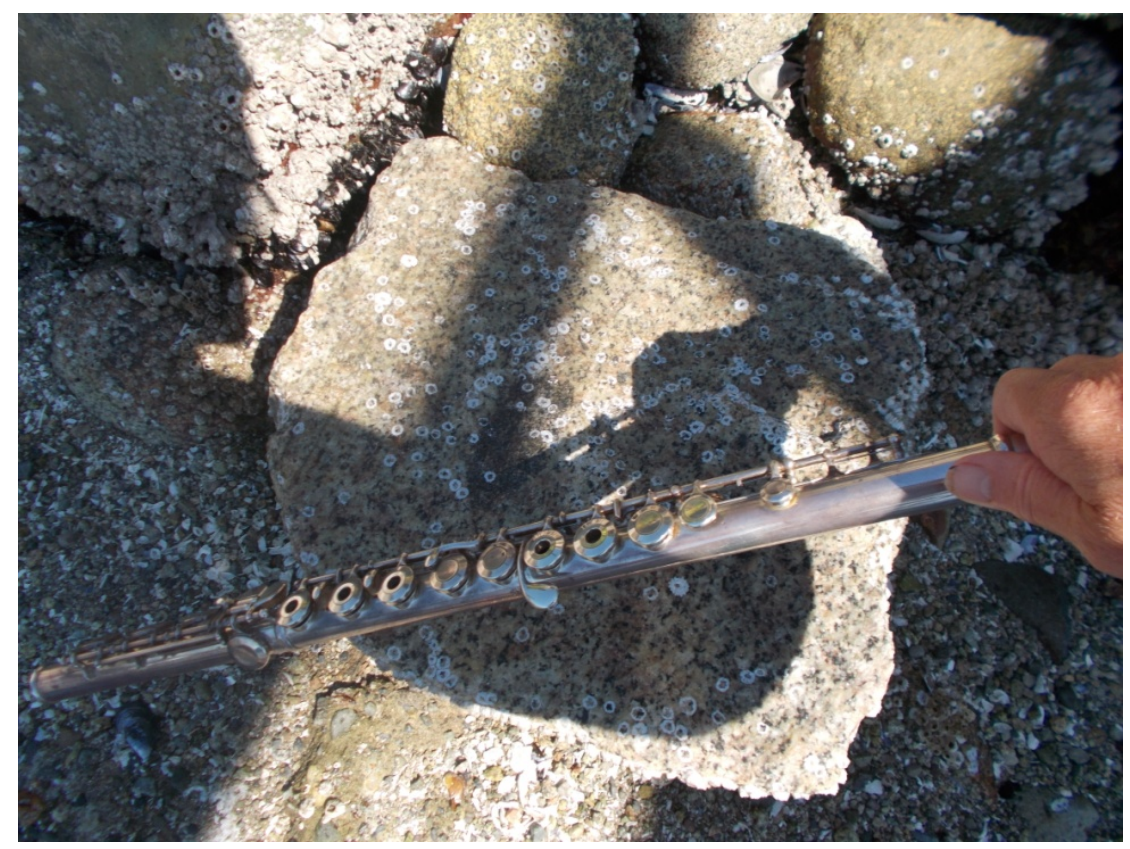

I release the need to seek, look beyond, because the answers are always right here somewhere near us and I reflect on my next choice to express Pedagogy transmits sustainability and sustainability transmits and translates pedagogy

Live in your hearing mind, the yogi shares

I listen for a moment to the inhalation that seems to penetrate my neck below my left ear. I feel tense muscles turn right, then slowly left. Opening up to my vision, I notice a group of four students chatting like good friends. My heaviness lifts slightly and I smile again thinking of these students as an orchestral brass section so necessary for sustainability, vital for a solid core, a responsive, malleable but strong spine, constant, reliable rhythm for every rehearsal, every performance. But, I am not a conductor totally in charge of the ultimate impact of collective renderings of sound, the transmitter of the transmitted...sharing of individual narratives of knowing and living through our art(s); I am only a member of this orchestra as I was as first chair flutist, prepared for occasional solos, occasional synchronicity. I listen to the four girls and find humour in knowing that stalwart brass sections often immerse their intensity in an ocean of sound that seem to drown out flute-sound.

I sense my pelvis tilt forward to take over but I press my core muscles in and up. My ribs relax; my lips relax. I prepare to perform, shoulders finding peace; I lean forward, knees slightly bent to support my torso weight and I drop my bag on a table. I realize I am humming into the chatter that changes key to a soft minor murmur and I take my flute case out of my bag

as if my movements

reveal a rising organic pulse layering through a waiting curious audience Synchronicity I feel eyes turn to me 
My next performance seems to emerge

from small sinews around my sacrum lying out of balance left to right

I feel cold silver on my lips

close my eyes to concentrate on my third eye on my forehead between my eyes

my place of intuition

solid blue sky free from restraints like windows and walls

taste freedom of moving air in sound

perform into vulnerability

sense surprise when I carefully assemble my flute’s sound

into realness of mutual gaze towards our self and 'other'

not the obvious

not the expected

not the passive view

I tumble into uncharted aesthetic gaze

as participant of inclusive choreography

of meaning

intersecting in dimensions of sound, movement, and space

I play my flute to my students; my torso falls forward and finds parallel space down my back from earth to sky and I sense and send tremulous elements through concrete to my welcoming feet. Slowly, I release each vertebra upon layers of inquiry lying peacefully on my lower spine, a rhizome with pulse, vibration deep in the earth...imminent sound.

My fingers and tongue synchronize without thought. I close my eyes and imagine my body balancing on the edge of the impatient ocean; I feel a green-salt-opaque rush as I dive, salt-full and completely at peace, into the ocean. Have I found my pace, my place of deep listening (Ramsay, 2009, p. 26)?

I offer a video of myself performing at an arts and education international conference. It begins with me playing my flute and now I am in duet with myself. This offering invites my students to be participant, co-authors as the classroom transforms into performative spaces not unlike multisite performances where dancer and researcher, Carol Stock (2011), describes a blending of performer and audience as areas of intersection where "the familiar is re-imaged and reimagined” (p. 3).

I sit for minutes on edges of stretched possibilities in anticipation close to anxiety like familiar yin poses of discomfort, not pain. I re-image loosening fascia healing emerging clarity of expression

Unique style or voice

invites acceptance

stops seeking answers

creates spaces of knowing in risk-taking and trust

I play

my arms remain in tremors of anticipation

shared discomfort

perhaps I sense reverberation of embarrassment

unpredictable introduction of instructor/musician/photographer/writer 
in the taking on

not just of our classroom

but our shared performance place or our shared "performance of place” (Kaye, 2000, p. 3) of exposing, revisiting un-accepting the accepted as we share our narratives

un-expecting the expected when we re-interpret

I play

I watch students respond to my vulnerable performance in stillness that awakens our venue where pedagogy simmers

in transient co-authored passages

where my constant critical review of my teaching practices are sustained by imagery and sound I play

In this venue, I will offer gifts to students such as Alice Munro's (1978) The Beggar Maid, where Munro intends to emerge into intercontextual performance spaces of words and feeling, shared. I seek synchronicity not only with Munro's intentions but also with her disclaimer for the cover-up of truth's emotion that damages uncertain beauty and, as a result, we have no choice but to become open to interrogative venues, multi-sites metaphorically constructed

to expose the obvious and lay bare

performance of raw emotion

with our art(s) expression of life experience

Like yin yoga poses

I feel unravelling

I feel revealing

I play

I play

and think how Munro's short story will assist me when I invite narrative response that feels the pulse of pedagogy in every sound-full transmission of meaning into contemplative spaces between literature and individual history

I will invite students to take Munro on

write about their Patrick, their Rose, their lack of loyalty, blind love, years of grief, life of love

I will interrupt discussions of practical approaches to teaching English finding balance between correcting mistakes and inviting unforeseen, unexplained expression where meaning is a process. Lorrie Neilson Glenn (2013) refers to novelist E. M. Forester who wondered how he would know what he was thinking until he saw the words (cited in James, Dobson, \& Leggo, p. 173). In my assignment requirements after a live Shakespeare production, a Vancouver Bard on the Beach class field trip, I will suggest that students respond in a genre of their choice and some will engage with predictable writing genre, perhaps sonnet form or narrative essay. I think of another former student.

A poet/visual artist responds through pen and ink drawings on rice paper stained by that dark night rain a document of her walk home 
alone from a Hamlet production

an artefact of poetic renderings in three dimensional

words and imagery

merging fear

loneliness, betrayal

I play

I play my flute in danger of automatic synchronicity, co-performance without careful reflection. I thrive in the pulse of a common breath and seek to expose the danger of slipping into loose rhythm disassociated with our living histories

a force

it attracts us to

conforming areas of easy resting places

of expression

expectation and predictability

We are a community of writers/educators who have commitment to our ongoing, reflexive inquiry that Gouzouasis, Irwin, Miles, and Gordon (2013) define as fully taking on a way of being in the world and negotiating personal engagement in a community of belonging with commitment to creating practices that trouble and address difference.

My flute finds moderate pace of my place with easy intervals in mid-octave, sustained notes, and a challenge to consecutively sound an "A" six times without repetition of purpose, with a drive forward, a slight crescendo, and care (Ramsay, 2009). Students watch my video on a large screen, a film of me playing the flute; I create synchronicity, a duet. Then as voice over my text, my life writing as critical inquiry creates ensemble co-creating and my students become integral in the synchronicity of embodiment and expression in performance, of realization of new pedagogy.

Our performance is about everything that matters and everything that does not matter everything honest deeply contemplative non-judgemental I play 


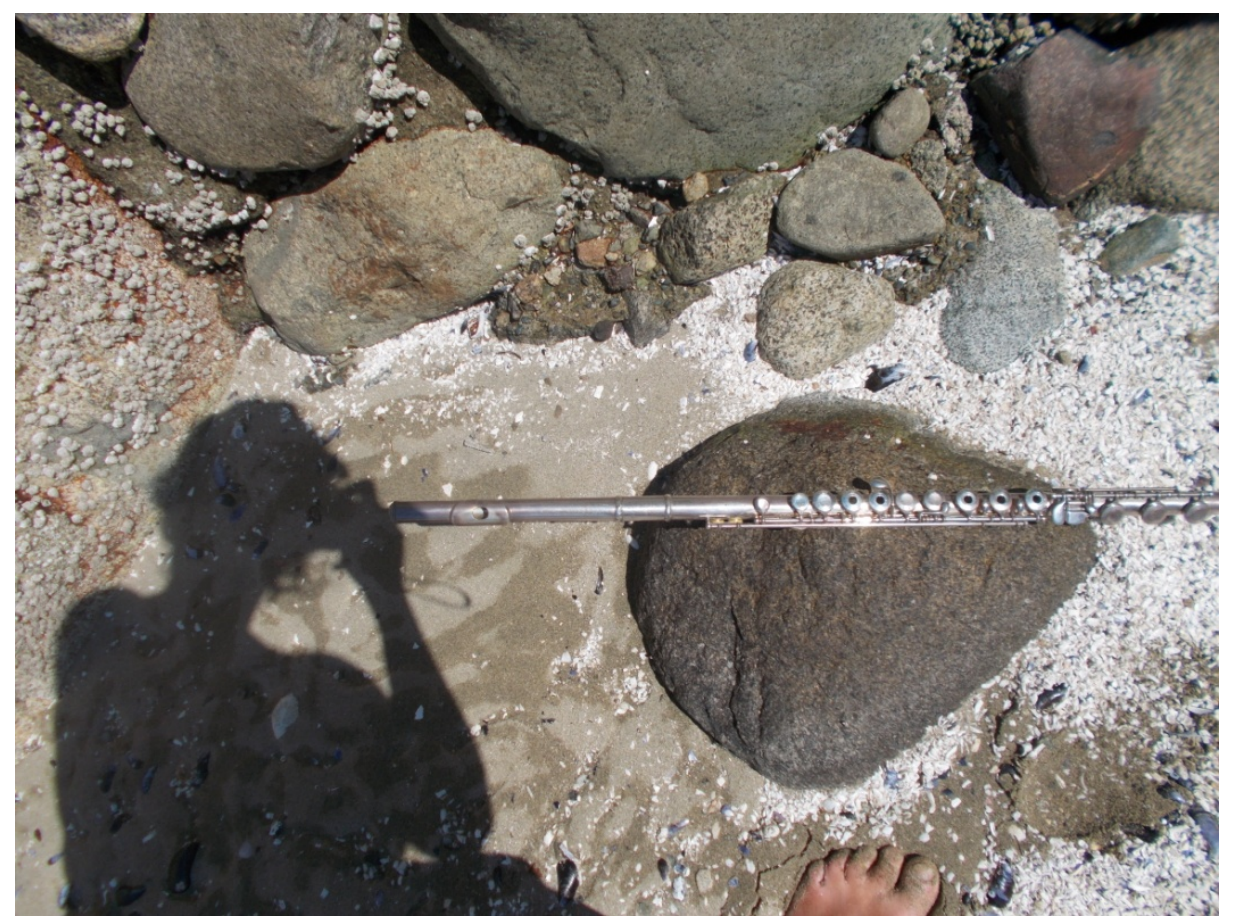

I am at one with the yogis breathing around me. I am at one. I think of a poem I recently wrote.

I play songs that remind me I am lost on rock walls like solid bone, screeches of frightened pheasants

take flight when I exhale pain like wild ponies racing with my heart

captured in imagery

by ancient ruins on top of a far off ridge

I am lost on dried dead grass prana without panic without familiar signposts of my yin and I wonder where we are 


\section{References}

Bakhtin, M. (1984). Problems of Dostoevsky’s poetics (C. Emerson, Trans.). Minneapolis, MN: University of Minnesota Press. (Original work published 1929)

CBC. Ideas. (2013, November 18). The Heart of the Beat Retrieved from http://www.cbc.ca/ideas/episodes/2013/11/18/the-heart-of-the-beat-1/

Clandinin, D. J., \& Connelly, F. M. (2000). Narrative inquiry: Experience and story in qualitative research. San Francisco, CA: Jossey-Bass.

Coles, L., \& Barrell, B. (2013). How can “transmediation” illuminate print and visual literacy. In K. James, T. M. Dobson, \& C. Leggo (Eds.), English in middle and secondary classrooms: Creative and critical advice from Canada`s teacher educators (pp. 109-114). Toronto, ON: Pearson.

Corness, G. (2008, December). The musical experience through the lens of embodiment. Leonardo Music Journal, 18, 21-24. doi:10.1162/lmj.2008.18.21

Cox, A. (2001). The mimetic hypothesis and embodied musical meaning. Musica Scientia: The Journal of the European Society for the Cognitive Sciences of Music, 5(2),195-212.

Glenn, L. N. (2013). Poetry has sprung to live in the contemporary world. How do I choose what poetry to teach. In K. James, T. M. Dobson, \& C. Leggo (Eds.). English in middle and secondary classrooms: Creative and critical advice from Canada`s teacher educators (pp. 172-178). Toronto, ON: Pearson.

Gouzouasis, P., Irwin, R. L., Miles E., \& Gordon, A. (2013). Commitments to a community of artistic inquiry: Becoming pedagogical through a/r/tography in teacher education. International Journal of Education and the Arts, 14(1), 1-23. Retrieved from http://www.ijea.org/v14n1/

Leggo, C. (2013). Exploring processes and products of learning. In K. James, T. M. Dobson, \& C. Leggo (Eds.), English in middle and secondary classrooms: Creative and critical advice from Canada `s teacher educators (pp. 179-191). Toronto, ON: Pearson.

Kaye, N. (2000). Site-specific art. New York, NY: Routedge.

Munro, A. (1978). Who do you think you are? Toronto, ON: Penguin Books.

Ramsay, L. L. (2009). Pedagogy of embodied voice: Reflective arts performance in teacher and special education. Unpublished PhD dissertation. Simon Fraser University

Richmond, S., \& Snowber, C. (2009). Landscapes of aesthetic education. Cambridge, Eng: Cambridge Scholars Publishing.

Stock, C. (2011). Creating new narratives through shared time and space: Performer/audience connections in multi-site dance events. In L. Caldwell (Ed.), Time together: Viewing and reviewing contemporary dance practice, Proceedings of the 2010 World Dance Alliance Global Summit, New York, 12 - 17 July. 1 (1). Retrieved from http://www.twu.edu/downloads/dance/Cheryl_Stock_Site_performer_audience_connecti ons_\%2821\%29.pdf 